\title{
Customer Service and Satisfaction: Competitive Advantage and Beyond
}

\author{
Stanley Bazan
}

This article examines how excellence in customer service and satisfaction can be a major source of competitive advantage and profits for small businesses. The costs and causes of poor service and satisfaction are discussed and special emphasis is given to the value of the lifelong customer. Methods to pursue the goal of completely satisfying customers 100 percent of the time are examined. Leadership, aggressive problem solving, problem-solving teams, and assessment of customer service are among the topics reviewed.

$\mathrm{I}$ n 1987, Time magazine ran a cover story entitled "Why Is Service so Bad?" In 1988, Bonnie Jansen of the U.S. Office of Consumer Affairs lamented that consumers are "sick and tired of being battered around; they're sick of getting poor service all the time."1 Numerous articles on customer satisfaction and service appeared in publications like Harvard Business Review in the early 1990 s and study upon study revealed that customers across a wide variety of industries reported low levels of customer service and satisfaction.

Most recently, joint studies by the University of Michigan Business School and the American Society for Quality Control reveal that customer satisfaction and service continue to be problematic in the U.S. economy. ${ }^{2}$ According to these studies, overall levels of customer satisfaction have fallen in two out of the past three years and customers were less satisfied in 1997 with supermarkets, department and discount stores, hotels, and fast-food-type restaurants than they were in 1996.

Given the notion that the single most important ingredient in the success of a new venture is the customer ${ }^{3}$ and that customer satisfaction and service are among the most important factors affecting a business unit's performance, ${ }^{4}$ it is clear that satisfying the customer must be a primary objective of entrepreneurs. In fact, 71 percent of small business owners feel that customer service and satisfaction is an area in which small companies can beat their big company rivals. ${ }^{5}$

Customer service and satisfaction represent a major source of competitive advantage for entrepreneurs because a properly focused small business is flexible and responsive enough to infuse the goal of completely satisfying its customers 100 percent of the time into all its employees and into every facet of its operations. Competitive advantage is defined in this article as the reason why a consumer would choose your business over another which provides similar goods or services.

This article begins by exploring the costs of customer dissatisfaction as well as some major sources of dissatisfaction and poor service. Next, a number of ways to achieve competitive advantage through excellence in customer satisfaction and service are reviewed. Goal setting, leadership, aggressive problem solving, problem-solving teams, and the assessment of customer service and satisfaction are also addressed.

\section{Economics of Customer Dissatisfaction}

A first step in pursuing competitive advantage through excellence in customer satisfaction and service is to fully understand the consequences of failure in these critical areas. The impact of poor service and satisfaction go far beyond the loss of a single sale, an unpleasant phone call, or a formal letter of complaint, and can have far-reaching impact on a firm's revenues and profits.

The direct financial impact of losing a customer can be astounding. For example, if your firm loses one customer per week for one year and these customers spend $\$ 20$ per week at the business, you will lose $\$ 26,520$ in revenues over the course of the year. If these customers spend $\$ 50$ per week, lost revenues total $\$ 66,300$; if they spend $\$ 100$ per week lost revenues in this scenario total $\$ 132,600$. Losing one customer per week who spends the relatively paltry sum of only $\$ 5$ per week for a period of one year would also yield a total loss of $\$ 6,630$. 
The impact of losing a customer forever is also staggering when the economic value of a lifelong customer is considered. The lifelong value of a loyal pizzeria customer is estimated to be $\$ 8,000$ and the average lifetime value of a Cadillac owner to a dealer is $\$ 332,000 .^{6}$

In terms of direct financial ramifications, it is five times more expensive to get a new customer than it is to retain an existing one. ${ }^{7}$ Additionally, reducing the defection of existing customers can impact the bottom line as reducing defections by a mere 5 percent has been shown to increase longterm profits by anywhere from 25 to 85 percent. $^{8}$

Less direct effects of dissatisfied customers such as negative word-of-mouth can also be significant. A landmark study conducted by the Technical Assistance Research Institute indicates that a dissatisfied customer will relate his or her bad experience to at least ten people. ${ }^{9}$ This study also shows that 13 percent of dissatisfied customers will tell their stories to more than twenty people. With whom will dissatisfied customers share their tales of pain and frustration? Both empirical research and conventional wisdom suggest the same answeranybody who will listen! The fact that that consumers tend to give more credence to negative, as opposed to positive or favorable, word-of-mouth only adds to the detrimental effects of negative word-of-mouth. ${ }^{10}$

Another set of costs associated with dissatisfied customers, especially in industrial sales, is the time, energy, and potential legal bills that are incurred trying to collect payments from customers who refuse to pay for a product or service that they consider to be unsatisfactory. Lastly, valuable time can also be spent responding to government agencies or consumer complaint bureaus. Records of complaints maintained by these agencies also do little to enhance the reputation of a business.

\section{Causes of Customer Dissatisfaction}

Sometimes it only takes one incident in a trading relationship to turn a customer away from a business. Therefore, in analyzing causes of dissatisfaction it should be remembered that the entire chain of events composing a transaction as a whole may only be as strong as the weakest link.

\section{Employee Attitudes}

The first cause of dissatisfaction is rooted in employee attitudes. An attitude problem might entail indifference, lack of respect, or rudeness to a customer. Some examples are:

- On the way to take a fifteen-minute break, a salesperson in a retail store notices a customer straining to reach a large item on an upper shelf. The salesperson avoids making eye contact as she proceeds to the employee lounge.

- A clerk at a grocery store is more interested in conversing with his friend at an adjoining register and fails to credit several coupons appropriately. When the customer asks him to pay more attention to checking out the groceries, the clerk roles his eyes and mutters something about "stupid coupons" under his breath.

- A customer with a new house is excited that her new dining room set is being delivered. She has been happy with the furniture store so far. When the delivery people show up one person does not take off his muddy boots and stains a carpet. The homeowner cleans the mud and looks for a new furniture store.

\section{Employee Ability}

Customers may also be dissatisfied when an employee is sincere but does not have the requisite knowledge or ability to properly serve the customer. These problems usually result from poor hiring practices or poor training programs. Consider these examples:

- A customer is frustrated with a salesperson's poor knowledge of the details of a special year-end inventory reduction sale.

- A person with extremely limited computer skills is assigned a sales position in an electronics department that sells a wide variety of computer hardware.

\section{Rules and Policies}

Company rules or policies might also cause dissatisfaction. These types of problems are usually the result of poorly conceived operating procedures. Problems of this type are often apparent when employees continually find 
themselves telling customers "I would like to but I really can't." Several examples are:

Company policy states that a store will not accept personal checks for purchases over $\$ 100$. A cashier tells a customer that she can not accept a check for the $\$ 104$ bicycle that she was going to bring to her nephew's birthday party that afternoon.

- A customer comes into a hardware store with a broken rake and exclaims, "I bought this here last week and it broke after I used it for two minutes." The store manager refuses to replace the rake with an identical one that he has in stock because store policy states that a receipt must be presented when a refund or exchange is made.

- A store clerk can not assist a customer in the back of the store because she is the only one on duty and she has to watch the register.

\section{Lack of Empathy}

Lack of empathy involves the unwillingness to see the customer's point of view when it comes to service and satisfaction. This frequently leads to discounting the concerns of the customer as inconsequential and labeling potentially serious problems as "no big deal." Some examples are:

- A mortgage company calling a customer two hours before a scheduled closing and explaining, "We should be able to do this tomorrow afternoon because there are still some escrow issues that need to be resolved. It's not a big deal, this happens all the time." The customer immediately calls work to request another day off and nervously calls the baby-sitter to see if he could come tomorrow afternoon instead.

- A service manager at a car dealership tells a customer, "Just drop your vehicle off and we'll see if we can get to it over the next couple days."

- A contractor returning a phone call and telling a customer, "You only get one visit for a free estimate and I already explained the job to you. After all, installing a new sidewalk isn't a big deal and it's only a $\$ 3,500$ job."

\section{Perceptions of Dishonesty}

Seemingly dishonest business practices are another source of customer dissatisfaction. Although only a fraction of entrepreneurs are intentionally dishonest, it is important to recognize that exorbitant claims about a product, overly optimistic promises, and an unwillingness to give a customer bad news can all be perceived as dishonesty. Examples of activities that can be construed by customers as being dishonest are:

- The upholstery on this couch is so tough that it will not stain, rip, or require professional cleaning even if you do have three-accident prone toddlers.

- A dispatcher excitedly tells a customer whose copier has just broken down that he will have someone over within thirty minutes and that the repair work will only take ten minutes. The technician, who arrives on the scene after an 80-mile drive and then spends four hours fixing the machine, wonders why the individual in charge of the copier seems so irate

- The account manager at an electrical supply house gets a call from a customer about an order that was supposed to arrive earlier that morning. He tells the customer that the order is "on the truck as we speak." The account manager hangs up and nervously calls his warehouse to see if the requested electrical components are in stock.

\section{Towards Complete Satisfaction}

Specific ways to build competitive advantage through excellence in customer satisfaction and service are explored below.

\section{Goals}

Developing appropriate goals and objectives is the first step in building competitive advantage through customer satisfaction and service. Although every business will be different in terms of specific performance objectives, there is little room for compromise in developing the overarching goal of the business. Every business 
seeking competitive advantage through service and satisfaction should adopt the goal of completely satisfying its customers 100 percent of the time. Satisfying the customer means that a product or service and all aspects of the delivery of that product or service will always meet or exceed the customer's expectations. More specific operational objectives appropriate to a particular business must also support this overall goal.

Although the goal outlined above seems somewhat intuitive (especially given the costs of dissatisfied customers), the components of this goal statement warrant additional discussion.

First, notice the emphasis on complete satisfaction. A study examining the impact of various levels of satisfaction on consumer behavior was conducted by John Larson of Opinion Research Corporation in Princeton, New Jersey. ${ }^{11}$ Larson examined the buying patterns of consumers who reported varied levels of satisfaction along the following scale: completely dissatisfied, dissatisfied, neutral, satisfied, completely satisfied. He found that completely satisfied customers were 42 percent more likely to be loyal customers than customers who were merely satisfied. Loyal customers represent repeat business and positive word-of-mouth which contribute to increased revenues. Completely satisfying customers and developing loyalty is so important that it is considered the most important driver of long-term financial performance for businesses of all sizes across a wide variety of industries.

Horst Schulze of the Ritz-Carlton Hotel Company provides an example for companies of all sizes: "Unless you have complete customer satisfaction-and I don't mean that they are just satisfied, I mean they are excited about what you are doing-you have to improve." 12

The concept of satisfying the customer 100 percent of the time should also be addressed. Although this is challenging to say the least, a business can never be complacent because it only takes one bad experience to turn a customer, and potentially the ten people he or she might relate their experience to, away from your business for life. Consistency of effort is just as important as quality of effort.

\section{Leadership}

The business owner must emanate an almost evangelical zeal to the goal of completely satisfying the customer 100 percent of the time. Leaders must communicate the importance of good service and satisfaction to every employee in the company and must set an example for everyone in the organization to follow. Even if there is only an owner and one employee in the company, that single employee can be inspired by observing the owner's actions. Business owners must also recognize and reward employees who demonstrate a total commitment to customer satisfaction and service.

\section{Aggressive Problem Solving}

Given the tremendous costs associated with a dissatisfied customer, aggressive steps must be taken to turn a less-than-satisfied customer into one that is completely satisfied. This may involve taking a relatively minor financial setback in the short run but the long-term rewards of completely satisfying a customer are worth it. Examples of such actions are:

- If the customer in the earlier scenario comes into your store with a rake that broke after it was used for two minutes and he says he bought it in your store but does not have a receipt, you should replace it if you sell the product in question.

- If a customer complains that his pizza was delivered cold and the crust was burnt, the customer should be given a coupon for a free pizza. Remember, the lifelong value of a loyal pizza eater is typically about $\$ 8,000$ and by making the next pizza free you will not only impress him with your sense of fairness but you will get another shot at his tastebuds, too.

- If a customer is not happy with the repairs on his air-conditioning system, send a service technician to his location as soon as possible even if it means paying overtime and not charging for the second service call.

Since cash flow is always an issue in small business, one might question the above tactics as

being overly aggressive or "giving" away the store. However, given the direct economic value 
of lifelong customers and the impact of positive word-of-mouth, these tactics, when applied with reasonable limits and with common sense applicable to the particular business and product, are appropriate in maximizing revenues and profits over time.

Entrepreneurs are also concerned that these strategies can result in being taken advantage of by dishonest customers and it is probable that some customers would lie to get a free pizza or a new rake at the expense of the seemingly gullible entrepreneur but this would be a very small minority. In considering specific responses to dissatisfied customers, the business owner has to evaluate the cost of being taken advantage of by an unscrupulous few versus the benefits of completely satisfying the majority of dissatisfied customers who have legitimate concerns.

In summary, when applied with common sense and reasonable discretion, the practice of aggressively seeking to completely satisfy a customer with a bad experience with a product or service will yield truly impressive financial results over the life of the business.

\section{Empowerment}

Empowerment is defined as the sharing of power with others. ${ }^{13}$ Entrepreneurs must give employees the discretion to do whatever it takes to make a customer completely satisfied. This means giving employees the discretion to solve problems on the spot. Business owners must also be ready to forgive mistakes when they share such power with employees or employees will become overly cautious and conservative when solving service or satisfaction problems. Remember that one of the safest moves an employee can make is to say "I would like to but I can't."

\section{Problem-solving Teams}

Problem-solving teams are groups who meet regularly to address on-going concerns in organizations. Depending on the company's size, at least one team should be composed to serve as a forum to discuss customer service and satisfaction issues. These teams should be charged with understanding the company's operations from the perspective of the customer. In very small companies, this team may just be the owner and a handful of employees. In addition to fixing specific problems, these teams reinforce the importance of customer service and satisfaction in the company.

\section{Assessment}

Understanding your strengths and weakness in customer satisfaction and service is essential if you are going to effectively pursue the goal of completely satisfying your customers 100 percent of the time. A business needs to assess its performance in satisfaction and service so that action may be taken to remedy any problems and more fully capitalize on any strengths. Additionally, because only 4 percent of dissatisfied customers will directly voice their dissatisfaction to you, ${ }^{14}$ a number of diverse methods of assessing customer service are reviewed in this section.

Listening. Despite the fact that 96 percent of customers won't complain directly to you, listening to customer complaints is one way to identify service and satisfaction problems. Although this seems intuitive, managers need to apply some specific skills when fielding verbal complaints. First, you need to avoid defensiveness in order to really concentrate on what the customer is saying. This is easier said than done especially when a customer is complaining about the business that you have nurtured and built. Try not to take complaints personally. Secondly, try to ascertain the exact nature of the problem so you can correct it for this customer as well as for others. It is far better to know that a customer's chicken soup was cold and that the soft drink was warm than to only know that the meal was terrible. Third, when conversing with a displeased customer, you not only have to ascertain the cause and extent of the problem, but you should take aggressive steps to correct any problem to completely satisfy the customer. Lastly, try to understand a problem from the customer's point of view and be as empathetic as possible.

Listening to employees can also be valuable in assessing customer satisfaction and service. It is important to ask employees about customer satisfaction and service in order to get a different

perspective than your own. Additionally, when a business begins to grow, the owner may not deal 
directly with customers so it is important that an owner solicits the input of those dealing directly with the customers on an on-going basis.

MBWA. The power of "management by walking around" should not be discounted in assessing customer satisfaction and service. ${ }^{15}$ MBWA simply involves making a deliberate effort to observe if customers are being completely satisfied with your business. For example, do customers look confused or lost in your store? Are there long lines at cash registers? Is your staff being courteous and helpful? Do customers look happy? Because the small business owner is usually extremely busy with a wide variety of responsibilities, deliberate efforts to attune one's senses to some specific elements of customer satisfaction and service can yield some interesting insights.

Surveys. The last method of assessing customer satisfaction and service involves the use of surveys. Surveys can take many forms but all are designed to evaluate general as well as specific sources of satisfaction and dissatisfaction.

Surveys can be conducted by phone, mail, or at the point of sale or purchase. ${ }^{16}$ Phone surveys are the most expensive but have higher response rates than mail surveys. The cost of point-ofpurchase surveys is cheapest but response rates vary tremendously depending on the specific business. Additionally, some businesses are more conducive to immediate evaluation by customers than others. For example, restaurants can make heavy use of point-of-purchase surveys because the business transaction has been completed, while businesses involved in auto repair can not rely heavily on point-of-purchase surveys because it may take several days or weeks for the customer to evaluate the repair work.

When designing surveys, it is important to remember that the longer the survey, the less likely customers are to respond to it. Customers are busy and do not want to spend a lot of time filling out a survey. Secondly, questions may be open-ended or may require respondents to answer via multiple choice or some type of numerical scales. An example of an open-ended question is: "Why were you satisfied or dissatisfied with our service?" Common numerically based scales can be composed of levels of satisfaction or can require the customer to indicate various levels of agreement or disagreement with specific statements in the survey.

A common scale directly addressing levels of satisfaction is the scale composed of these items: completely dissatisfied, dissatisfied, neutral, satisfied, completely satisfied. A scale that is typically used to measure agreement with a particular statement includes: strongly disagree, disagree, undecided, agree, and strongly agree.

Although designing surveys can be complex and has received only limited attention in this article, a good technique for small business people is to start a collection of satisfaction surveys that you can pick up at other businesses. In other words, do not try to "reinvent the wheel" by trying to set up a survey without a few examples. Review some existing surveys and then modify the questions and response formats to suit your specific needs.

Entrepreneurs should think about instances when they either responded to or ignored surveys of these types. For example, how many times would you have completed a satisfaction survey in a restaurant but they did not provide you with a pencil? Also how often do you ignore a survey because there is "nothing in it" for you?

One technique of generating responses is to enter people in a drawing or contest when they fill out a survey. This technique works well in generating feedback from satisfied customers but can sometimes further irritate dissatisfied customers. With respect to response rates, do not be disappointed in what may seem like a low number of responses. Draw on personal experience to devise ways to improve participation.

\section{Conclusions}

This article has explored the costs and causes of poor customer service and satisfaction. Special emphasis was given to the astounding costs of poor service and dissatisfaction as well as the staggering economic value of lifelong customers.

Employee attitudes, the lack of employee ability, restrictive rules and policies, and perceived dishonesty were identified as sources of dissatisfaction and poor customer service.

Methods to achieve competitive advantage by pursuing the goal of completely satisfying customers 100 percent of the time were also reviewed. Goal setting, leadership, aggressive 
problem solving, and assessment were discussed. Methods of assessment include listening, management by walking around, and the use of surveys.

\section{Endnotes}

1. Matulis, S., "The Customer Is King," Entrepreneur, September 1988, p. 19.

2. Fierman, J., "Americans Can't Get No Satisfaction," Fortune, December 11, 1995, pp. 186-194;

Davis, J. E., "Americans Are More Finicky than Ever," Fortune, February 3, 1997, pp. 108-110;

Grant, L., "Your Customers Are Telling the Truth," Fortune, February 16, 1998, pp. 164-166.

3. Cannie, J. K., Keeping Customers for Life. New York: AMACOM, 1991.

4. Buzzel, R. D., and B. T. Gale, The PIMS Principles: Linking Strategy to Performance, New York: Free Press, 1987.

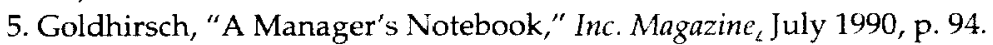

6. Heskett, J., T. Jones, G. Loveman, E. J. Sasser, Jr,, and K. Schlesinger, L., "Putting the Serviceprofit Chain to Work, Harvard Business Review, March-April 1994, p. 164-174.

7. Desatnick, R. L., Managing to Keep the Customer. San Francisco: Jossey-Bass, 1987.

8. Reichheld, F. F., and W. E. Sasser, Jr., "Zero Defections: Quality Comes to Services," Harvard Business Review, September-October 1990, pp. 105-111.

9. Technical Assistance Research Programs Institute, Consumer Complaint Handling in America: An Update Study, Washington, D.C.: U.S. Office of Consumer Affairs, 1986.

10. Lutz, R. J., "Changing Brand Attitudes through Modification of Cognitive Structure," Journal of Consumer Research, March 1975, pp. 49-59.

11. Jones, T. O. and W. E. Sasser, Jr. "Why Satisfied Customers Defect," Harvard Business Review, November-December 1995, pp. 88-89.

12. Treacy, M., and F. Wiersema, "Customer Intimacy and Other Value Disciplines," Harvard Business Review, January-February 1993, pp. 84-93.

13. Conger, J. A., "Leadership: The Art of Empowering Others, Academy of Management Executive 3 no. 1 (1989), pp. 17-24.

14. Technical Assistance Research Programs Institute, Consumer Complaint Handling in America: An Update Study.

15. Peters, T. and N. Austin, A Passion for Excellence. New York, Random House, 1985.

16. Albrecht, K. and L. J. Bradford, The Service Advantage. Homewood, Il; Dow-Jones-Irwin, 1990.

\section{NEJE}

Dr. Stanley Bazan currently teaches small business management, strategic management, and organizational behavior at Western Connecticut State University. He holds a BSBA from Western New England College and an MBA and Ph.D. in management from the University of Connecticut. Dr. Bazan is an active member of the Eastern Academy of Management and serves on the board of directors of the New England Business Administration Association. 